
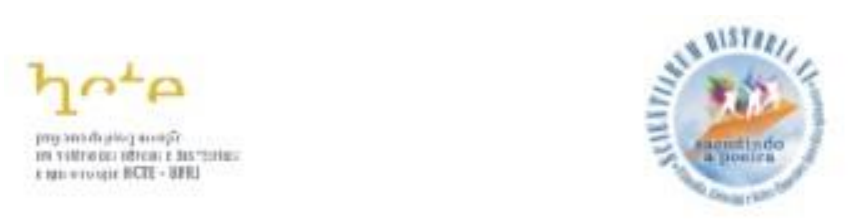

\title{
Espaços não formais de ensino: reflexões sobre as possibilidades de abordar temas transversais
}

\section{Non-formal teaching spaces: reflections on the possibilities of approach transversal themes}

\author{
Adriana Tavares dos Santos \\ Mestrado Profissional em Química em Rede Nacional (PROFQUI), Universidade \\ Federal do Rio de Janeiro. \\ Secretaria de Estado da Educação de Santa Catarina, EEB Presidente Juscelino \\ Kubitschek. \\ Grupo Interdisciplinar de Educação, Eletroquímica, Saúde, Ambiente e Arte \\ (GIEESAA/UFRJ).
}

Grupo Interinstitucional e Multidisciplinar de Ensino, Pesquisa e Extensão em Ciências (GIMEnPEC/UFRJ).

adrivares@pos.iq.ufrj.br

orcid.org/0000-0003-4314-6395

\section{Priscila Tamiasso-Martinhon}

Departamento de Físico-Química, Universidade Federal do Rio de Janeiro

CEEQuim/UFRJ, PROFQUI/UFRJ, PEQui/UFRJ.

Grupo Interdisciplinar de Educação, Eletroquímica, Saúde, Ambiente e Arte (GIEESAA/UFRJ).

Grupo Interinstitucional e Multidisciplinar de Ensino, Pesquisa e Extensão em Ciências (GIMEnPEC/UFRJ).

pris-martinhon@hotmail.com

orcid.org/0000-0001-6141-3755

\begin{abstract}
Angela Sanches Rocha
Departamento de Físico-Química, Universidade do Estado do Rio de Janeiro.

Programa de Pós-Graduação em Química (PPGQ/ UERJ).

Grupo Interdisciplinar de Educação, Eletroquímica, Saúde, Ambiente e Arte (GIEESAA/UFRJ).
\end{abstract}

Grupo Interinstitucional e Multidisciplinar de Ensino, Pesquisa e Extensão em Ciências (GIMEnPEC/UFRJ).

angela.sanches.rocha@gmail.com

orcid.org/0000-0002-3575-4844 


\section{Célia Sousa}

Departamento de Físico-Química, Universidade Federal do Rio de Janeiro PROFQUI/UFRJ, EAD (UAB/ UFRJ).

Grupo Interdisciplinar de Educação, Eletroquímica, Saúde, Ambiente e Arte (GIEESAA/UFRJ)

Grupo Interinstitucional e Multidisciplinar de Ensino, Pesquisa e Extensão em Ciências (GIMEnPEC/UFRJ). sousa@iq.ufrj.br orcid.org/0000-0001-8988-3724

Resumo. A escola é considerada uma instituição que tem como função desenvolver a formação dos educandos, dando-lhes acesso aos conhecimentos teóricos e práticos estabelecidos pela sociedade da qual fazem parte. Porém, o processo educacional pode ultrapassar os muros da escola e ir além da sala de aula. As relações sociais vividas por cada um fazem-no adquirir conhecimentos por meio de suas próprias experiências,relacionadas com sua trajetória. As atividades extraclassese mostram importantes no processo educacional, podendo ocorrer em diversos espaços presentes na comunidade, onde os estudantes possam ter uma educação mais contextualizada que incluem os temas transversais. Neste trabalho faz-se um convite à reflexão sobre os espaços não formais de aprendizado ligados ao tema transversal meio ambiente, sob viés do ensino de Ciências.

Palavras-chave: Educação não formal. Educação ambiental. Temas transversais.

Abstract.The school is considered an institution whose function is to develop the training of students, giving them access to the theoretical and practical knowledge established by the society of which they are a part. However, the educational process can go beyond the walls of the school and go beyond the classroom. Social relationships experienced by each do they acquire knowledge through their own experiences related to his career. Extra-class activities are important in the educational process and can occur in different spaces present in the community, where students can have a more contextualized education that includes transversal themes. In this work, an 
invitation is made to reflection on non-formal learning spaces linked a transversal theme environmental for Science teaching.

Keywords: Non-formal education. Environmental education. Transversal themes.

\author{
Recebido: 01/10/2018 Aceito: 27/10/2018 Publicado: 05/11/2018
}

\title{
1. Introdução
}

Nas últimas décadas, novos métodos têm sido desenvolvidos, apresentados e discutidos no meio educacional, no qual, assim como na sociedade, existem muitas desigualdades e meios sociais diversificados, de modo que cada estudante é considerado um indivíduo singular. Sob esta lente, este aspecto representa um desafio a parte para educadores e pesquisadores da educação e profundas mudanças ocorreram nas vertentes sóciohistóricas no campo da educação.

Logo, o termo educação tem se transformado e se tornado mais amplo, atingindo novos horizontes, não se limitando apenas àquela ideia de que só ocorre dentro do espaço escolar formal, dedicado especificamente para desenvolvimento do processo de ensino e aprendizagem. Um novo campo educacional fora dos muros das escolas, conhecido como educação não formal, tem sido reconhecido com apresentando grande valor no processo educativo, já que nele, o estudante pode relacionar conhecimento com o meio em que vive e trocar ideias com outras pessoas (GOHN, 2004). De acordo com a Lei de Diretrizes e Bases da Educação Nacional, Lei no 9394 de 20 de dezembro de 1996 (LDB, 1996), a educação é considerada realmente ampla, pois segundo esta lei: “...a educação abrange os processos formativos que se desenvolvem na vida familiar, na convivência humana, no trabalho, nas instituições de ensino e pesquisa, nos movimentos sociais e organizações da sociedade civil e nas manifestações culturais".

As teorias e práticas no ramo educativo têm ocasionado pesquisas na área de atividades em ambientes não formais, permitindo um maior esclarecimento e avanço da educação com um caráter mais humano, mais sociável. Esse novo método veio para acrescentar ao processo educativo formal novas informações e habilidades, e não para substituí-lo. Os indivíduos se tornam os protagonistas de suas próprias histórias, construindo novos 
saberes e desenvolvendo olhares mais críticos. De acordo com Gonh (2011), a educação não formal é uma possibilidade de produção de conhecimento em territórios fora das estruturas curriculares da educação formal.

$\mathrm{O}$ docente, se apresentando como educador, necessita relacionar os temas com a vivência e com os valores da comunidade, tornando-a mais participativa nas atividades pedagógicas, onde ocorre uma troca de saberes, em outras palavras: todos ensinam e todos aprendem. Segundo Freire (2005, p.44): "Se estivesse claro para nós que foi aprendendo que percebemos ser possível ensinar, teríamos entendido com facilidade a importância das experiências informais nas ruas, nas praças, no trabalho, nas salas de aula das escolas, nos pátios dos recreios, em que variados gestos de alunos, de pessoal administrativo, de pessoal docente se cruzam cheios de significação".

Logo, existe uma relação dialógica entre educador e educando no processo educacional em ambientes não formais, todos os participantes possuem o direito a expor suas colocações e suas experiências, a fim de tornar a atividade mais esclarecedora. Evidentemente esta prática também existe nos espaços formais, mas é nos espaços não formais que este aspecto se torna mais proeminente.

Para Vygotsky (1987), “o conhecimento é transferido daqueles que o detêm para aqueles que querem adquiri-lo, estabelecendo uma relação entre a educação formal (conceitos científicos) e a informal (conceitos espontâneos)". O desenvolvimento cognitivo pode dar-se pelo processo de ensinar tornando possível a aprendizagem, ou seja, o esforço de adquirir conhecimentos.

Nesta perspectiva, o presente trabalho tem como ideia principal realizar um convite à reflexão sobre a abordagem do tema transversal meio ambiente, em espaços educativos não formais de maneira interdisciplinar, no âmbito do ensino de ciências. Este tipo de reflexão e abordagem é uma tendência na sociedade contemporânea na qual o acesso de informação é grande e o senso crítico termina por ser pouco trabalhado, apesar de ser essencial na formação do cidadão consciente.

\section{A educação não formal}

A educação formal, educação informal e educação não formal, foram diferenciadas por Marandino (2017), tendo por base o trabalho de Smith (1996). De acordo com as 
informações apresentadas no Quadro 1, é possível observar as definições das três vertentes de educação, com suas principais características, tornando claras as diferenças entre elas.

Nos espaços de educação não formais o educador possui como propósito dar oportunidade ao sujeito de obter uma formação mais humanística, possibilitando a construção de sua identidade, se tornando mais comprometido com o exercício da cidadania.

Quadro 1. Definição das três vertentes de educação.

\begin{tabular}{|c|c|}
\hline $\begin{array}{c}\text { Educação } \\
\text { formal }\end{array}$ & $\begin{array}{l}\text { Sistema de educação hierarquicamente estruturado e } \\
\text { cronologicamente graduado, da escola primária à universidade, } \\
\text { incluindo os estudos acadêmicos e as variedades de programas } \\
\text { especializados e de instituições de treinamento técnico e profissional. }\end{array}$ \\
\hline $\begin{array}{c}\text { Educação não } \\
\text { formal }\end{array}$ & $\begin{array}{l}\text { Qualquer atividade organizada fora do sistema formal de educação, } \\
\text { operando separadamente ou como parte de uma atividade mais ampla, } \\
\text { que pretende servir a clientes previamente identificados como } \\
\text { aprendizes e que possui objetivos de aprendizagem. }\end{array}$ \\
\hline $\begin{array}{c}\text { Educação } \\
\text { informal }\end{array}$ & $\begin{array}{l}\text { Verdadeiro processo realizado ao longo da vida em que cada } \\
\text { indivíduo adquire atitudes, valores, procedimentos e conhecimentos } \\
\text { da experiência cotidiana e das influências educativas de seu meio - na } \\
\text { família, no trabalho, no lazer e nas diversas mídias de massa. }\end{array}$ \\
\hline
\end{tabular}

É importante ter em mente que a escola tem um caráter sociopolítico de formar cidadãos, e nesse contexto, a exploração de ambientes externos ao espaço formal pode contribuir de maneira decisiva. A exploração de ambientes pode propiciar discussões que estimulem o senso crítico e a capacidade investigativa, se devidamente orientado por um educador.

\section{A Educação Ambiental na categoria não formal}

Segundo os PCN (BRASIL,1997) tem-se que: “A educação para a cidadania requer, portanto, que questões sociais sejam apresentadas para a aprendizagem e a reflexão dos 
alunos.", com base nestas ideias, os temas transversais foram propostos de modo a serem incluídos no currículo de forma inter e transdisciplinar.

Segundo este texto, os temas transversais são: Ética, Meio Ambiente, Pluralidade Cultural, Saúde e Orientação Sexual, e os professores são convidados a trabalharem estes temas em suas aulas.

Entendemos que a ética é um tema que permeia todos os outros temas, por dizer respeito às condutas humanas que, permeiam o "como agir perante os outros" com respeito aos direitos e deveres dos outros.

No âmbito das ciências exatas e da natureza, existem vários tipos de abordagens que podem ser utilizadas, sendo importante enfatizar que, o respeito aos direitos do outro eao meio ambiente, além de certos cuidados com a saúde, só se fazem de forma plena quando o indivíduo tem pleno conhecimento e consciência do porque das coisas e das consequências de seus atos. Portanto, isto só é possível por meio da educação, o cidadão só é capaz de exercer sua cidadania plenamente se não for um mero repetidor de atitudes, ou seja, por meio do conhecimento.

Dentre os espaços não formais de educação, podemos citar: museus, praças, parques, florestas, estações de tratamento de água, fábricas de reciclagem, praias, rios ou mesmo a cozinha. Sob o aspecto da abordagem de ciências serão apresentadas algumas ideias básicas que podem ser utilizadas nestes espaços, que em geral são realizadas por meio de visitas guiadas e planejadas por professores.

Os museus são os espaços mais ricos para esta prática, principalmente por apresentarem uma grande quantidade de material agrupado por assunto num mesmo ambiente. Também existe a possibilidade de visita de diferentes museus, com temáticas diferentes, o que aumenta as possibilidades. Para abordagem específica de meio ambiente, os museus naturais são os preferidos. É possível apresentar animais extintos e discutir os motivos pelos quais eles foram extintos, que podem estar associados a ações antropogênicas ou simplesmente de mudanças climáticas e de variações da composição da atmosfera, devido a mudanças naturais na terra. O professor pode aproveitar este momento para discutir transformações físicas e químicas e como a vida se adapta e reage a estas. 
Nos parques e florestas é possível abordar os aspectos típicos de ambientes ao ar livre, como o céu, as plantas, os animais e como estes precisam de um equilíbrio para estarem em harmonia. A intervenção do homem nestes ambientes pode ser enfatizada e o papel que temos que assumir. Também pode-se trabalhar a física envolvida na movimentação dos corpos, como o vôo das aves; as cores e propriedades dos materiais que estão no entorno; porque o vento se forma; a diversidade da fauna e flora do local e suas características.

As estações de tratamento de água são locais muito interessantes para se trabalhar conteúdos de química, como processos de separação e reações químicas. Também os aspectos ambientais devem ser abordados, uma vez que as fontes de água pura são cada vez mais escassas no mundo e a produção de esgoto cresce assustadoramente.

Nas fábricas de reciclagem e aterros é possível que eles tenham noção exata da quantidade de lixo que geramos e os cuidados que devemos ter para um consumo consciente. O consumismo e geração de lixo eletrônico é um dos grandes problemas da geração atual e este aspecto pode e deve ser discutido. A reciclagem de diferentes materiais também é um processo muito rico para estudo de propriedades de diferentes substâncias e reatividade.

Visitas a praias e rios, além de propiciarem momentos prazerosos, também podem servir para direcionar várias abordagens. As características da areia, pedras, conchas e o mar podem ser discutidos em termos de suas composições. Os animais presentes também podem ser explorados e investigados, mas, sem sombra de dúvidas, estes ambientes são muito propícios para discussões sobre os aspectos ligados ao meio ambiente. A água é essencial para a vida no planeta e a poluição causada pelo homem causa contaminação de mares e rios, além dos danos que os plásticos causam para a vida marinha e nos rios.

Por último, a cozinha da própria escola pode ser utilizada como espaço não formal para aprendizagem de vários aspectos das ciências e, sob o ponto de vista da educação ambiental, é possível discutir e abordar o uso consciente de água e a geração de lixo. A separação e limpeza do lixo reciclável são importantes nos locais em que existe coleta seletiva. Outro aspecto que normalmente não se considera é o descarte de óleo usado, que é realizado geralmente nas residências pelo ralo doméstico, depois de ser misturado 
com sabão por algumas pessoas. O descarte de pilhas, baterias e eletrônicos também pode ser trabalhado neste momento.

É importante estarmos alertas que atividades educativas voltadas para as questões ambientais podem ser essenciais para a mudança no quadro dos impactos ambientais, pois os cidadãos se tornam capazes de respeitar os direitos, deveres e pensar nas futuras gerações. Possui como função levar informações para a sociedade sobre a importância de se ter responsabilidades sobre o meio ambiente, voltados para uma mudança social, com uma formação contínua. Daí a necessidade de se ter a educação ambiental nos espaços formais e não formais.

Também vale a pena ressaltar que os alunos são agentes multiplicadores, levando este conhecimento para sua família e amigos, e, quando esta aprendizagem ocorre fora da escola, pode fazer com que o aluno se sinta mais impelido a disseminá-la com aqueles com que convive.

\section{Conclusões}

A educação não formal tem como uma das principais vantagens o fato de poder se realizar de maneira interdisciplinar, incluindo as todas disciplinas e de formas variadas. A educação em espaços não formais poderá ocorrer em diversos espaços, sendo assim preparando e desenvolvendo o indivíduo para o caminho de sua vida, dando apoio a várias posições, seja ela, econômica, social, ambiental ou científica, e se tratando do mundo globalizado, a tecnológica também. No contexto ambiental a participação da cidadania se mostra fundamental para um melhor convívio em relação com o meio físico e o natural, podendo abordar a educação ambiental em diferentes esferas.

Espaços não formais de educação podem ser considerados um dos principais meios da divulgação científica de forma transdisciplinar, auxiliando no ensino de ciências. Mostrando-se ser importante tanto quanto a educação formal, esses espaços estimulam a curiosidade dos frequentadores, podendo suprir algumas necessidades, como por exemplo, a falta de um laboratório ou recursos audiovisuais. 


\section{Referências}

BRASIL, Ministério da Educação, Parâmetros Curriculares Nacionais, Brasília, 1997.

FREIRE, P. Pedagogia da autonomia: saberes necessários à prática educativa. 31 . Ed. São Paulo: Paz e Terra, 2005.

GOHN, M. G. M. Educação não formal e cultura política: impactos sobre o associativo do terceiro setor. $2^{\mathrm{a}}$ ed. São Paulo: Cortez, 2011.

GOHN, M. G. M.A educação não-formal e a relação escola-comunidade. EccoS Revista Científica, v. 6, n. 2, p. 39-65, 2004.

LDB - Leis de Diretrizes e Bases. Lei $\mathrm{n}^{\circ}$ 9.394. 1996.Disponível em:<http://portal.mec.gov.br/seed/arquivos/pdf/tvescola/leis/lein9394.pdf> Acesso em outubro de 2018

MARANDINO, Martha. Faz sentido ainda propor a separação entre os termos educação formal, não formal e informal? Ciênc. educ. (Bauru), Bauru, v. 23, n. 4, p. 811-816, Dec. 2017. Disponível em: $<$ http://www.scielo.br/scielo.php?script=sci_arttext\&pid=S151673132017000400811\&lng=en\&nrm=iso>. Acesso em: 09 Out. 2018.

SMITH, M. K. What is non-formal education?1996. Disponível em: https://infed.org/mobi/what-is-non-formal-education/. Acesso em 28 Set. 2018.

VYGOTSKY, L. A formação social da mente. São Paulo: Martins Fontes, 1987. 